\title{
Physical Characterization of Drug Loaded Microcapsules and Controlled In Vitro Release Study
}

\author{
S. Jaya*, T.D. Durance and R. Wang \\ University of British Columbia, 2205, East Mall, Vancouver BC, V6T 1Z4, Canada
}

\begin{abstract}
Microencapsulation of model drug, acetylsalicylic acid into bio-based polymer, alginate- pectin matrix and chitosan had been undertaken in this work to characterize the microcapsules based on their composition. Alginate-pectin with the proportion of 40:60 solution was prepared with $0.3 \mathrm{~g}$ of drug. This mix was homogenized and atomized using nitrogen gas into $1.0 \mathrm{M}$ calcium chloride solution to form sol-gel microcapsules. $0.3 \mathrm{~g}$ concentration of the drug solution was prepared with $2 \%$ glacial acetic acid and $2 \mathrm{~g}$ of chitosan was mixed into that and homogenized using sonicator. Microcapsules were prepared after crosslinking the drug encapsulated chitosan using glutaraldehyde. Drug loaded microcapsules were dried using microwave energy under vacuum at low temperature. Scanning electron microscopy graphs showed that microcapsules have porous and rough surfaces. Fourier Transform Infrared Spectroscopy analysis on the microcapsules confirmed the presence of drug in the polymer matrix. X-ray diffraction pattern showed that the microstructure was more like an amorphous pattern. Drug release of the microcapsules was tested in three different $\mathrm{pH}$ levels of 1.2, 7.4 and 8.2. Slow and controlled release of drug was observed at all the $\mathrm{pH}$ levels. Over all, the drug release percentage was higher in acidic $\mathrm{pH}$ and lower in alkali $\mathrm{pH}$.
\end{abstract}

Keywords: Microcapsule, drug release, alginate, pectin, chitosan, acetyl salicylic acid.

\section{INTRODUCTION}

Natural polymers provide great advantages in biomedical applications such as drug delivery and tissue engineering (scaffolding). They are biocompatible, non toxic and biodegradable materials. Also, they have good potential to incorporate drugs, enzymes, bioactive components etc. [1, 2]. Alginate has been used by many researchers for controlled delivery of incorporated materials [3-5]. Alginate is a naturally occurring polysaccharide obtained from marine brown algae. It is composed of linear copolymers of 1, 4linked $\beta$-D mannuronic acid and $\alpha$-L gulcuronic acid. It gels in the presence of divalent cation like calcium. Microspheres produced using alginate has been used for the encapsulation of wide varieties of bioactive materials, proteins, enzymes, micronutrients, antibodies etc. [6-8]. It was proved that calcium-alginate microsphere encapsulated with insulin by extrusion process gave $65 \%$ encapsulation efficiency [9]. Bio-adhesive nature of alginate with mucosal membrane will help to get intimate contact between intestinal mucosa and lower sized microspheres $[5,10,11]$.

Pectin is another polymer (polysaccharide) found in the cell wall of plants. It has high molecular weight heteropolymers containing a $65 \%$ (by weight) of $\mathrm{D}$ galacturonic acid units which is joined to one another in chains by means of $\propto(1 \rightarrow 4)$ glycosidic linkages. Galacturonic acid is structurally similar to gulcuronic and mannuronic acids of alginate [12]. Crosslinking of pectin with calcium ions gives gel formation, as in the case of

*Address correspondence to this author at the University of British Columbia, 2205, East Mall, Vancouver BC, V6T 1Z4, Canada; Tel: 1 (604) 822- 4707; Fax: 1 (604) 822 5143; E-mail: jsundaram3@gmail.com alginate [13-15]. Microcapsules containing only alginate, cross-lined with calcium may not be sufficient to give better drug encapsulation. Therefore, incorporating low methoxy pectin in the polymer matrix is expected to increase the efficiency of encapsulation [16].

Chitosan is a cationic linear polysaccharide. It is non toxic and biodegradable. It is $\beta(1 \rightarrow 4)$ linked biopolymer composed of 2 -amino-2-deoxy- $\beta$-D glucan combined by glycosidic linkages. Chitosan consists of large number of amine groups which are corresponds with the interaction between chitosan and many other substances. Chitosan gives unique functional, nutritional, and biomedical properties [1719]. Chitosan has been used for many biomedical and pharmaceutical applications to improve drug delivery as well as for controlled delivery [20,21]. In case of drug delivery applications chitosan has been employed for preparation of drug loaded microcapsules/microspheres and are used to provide controlled drug release and improve bioavailability of the drugs [22]. Cross linking of chitosan with glutaraldehyde gives three dimensional network and increases the internal surface area for absorption. Glutaraldehyde has been commonly used in many cross linking process of chitosan. In general aldehyde groups are highly active and readily form Schiff bases with amino groups [23].

Several oncology-related experimental studies showed that non steroidal anti-inflammatory drugs (NSAIDS) could be used as cancer chemo-preventive agents [24]. It is soluble in both water and alcohol. Long term use of aspirin, which is metabolized into salicylic acid, has been shown to reduce the risk of colon, breast, prostate, lung and skin cancer [24]. It enables better for prevention and treatment. Research conducted on aspirin, related to cardiovascular disease, 
proved that it reduced the risk of cardiovascular diseases for women, when it was used as pain relief medicine [25]. Antiinflammatory nature of salicylates reduces tumour cell proliferation by inhibiting thymine dimer formation required for DNA replication [26, 27]. Other recent research literatures said that the use of salicylates could prevent skin cancer due to UV exposure in addition to its well known activity as a keratolytic agent [28,29].

Encapsulation techniques have been used extensively to entrap drugs and bioactive compounds and control their release into the gastrointestinal tract [1]. Several techniques were developed to produce encapsulated microspheres. Drug delivery system developed with microsphere might increases the life span of the active ingredients encapsulated inside and control the release. Because of its small size, that have large surface to volume ratio, which is very much suitable for controlled delivery. Microencapsulation offers many advantages that include increased stability, prolonged in vivo half-life, reduction of possible adverse side effects, concentration of the drug resulting in lower required doses, and ease of administration. Many techniques are available for micro encapsulation such as spray drying, spray cooling, extrusion, freeze-drying, co-crystallization etc. In this study, spraying and ultrasonic waves were used to make encapsulation and application of microwave energy under vacuum was attempted to dry the microcapsules. The objectives of this study are:

1. to develop a stable gel polymer matrix consisting of alginate-pectin and chitosan microcapsules to encapsulate the selected drug, acetyl salicylic acid (aspirin);

2. to characterize the microcapsules using scanning electron microscopy (SEM), X-ray diffraction and Fourier Transform Infra Red Spectroscopy (FTIR) techniques;

3. to study the In vitro drug release characterization of the microcapsules at different $\mathrm{pH}$ levels of releasing media.

\section{MATERIALS AND METHODS}

\section{Materials}

Samples of sodium alginate (TICA- algin HG 400) and Pectin (LM 35) in powdered form were received from TIC GUMS, USA. Acetyl salicylic acid (aspirin), chitosan (powder), glutaraldehyde, acetic acid and calcium chloride were purchased from Sigma (USA). Sodium phosphate monobasic $\left(\mathrm{NaH}_{2} \mathrm{PO}_{4}\right)$, Sodium Phosphate Dibasic $\left(\mathrm{Na}_{2} \mathrm{HPO}_{4}\right)$, Sodium Chloride $(\mathrm{NaCl})$, Potassium Chloride $(\mathrm{KCl})$, Potassium Phosphate Monobasic $\left(\mathrm{KH}_{2} \mathrm{PO}_{4}\right)$ and Hydrochloric acid $(\mathrm{HCl})$ were purchased from Fisher chemicals, Canada.

\section{Preparation of Drug Encapsulated Microspheres}

Preparation of drug encapsulated microcapsule has been given in Fig. (1a, b) as process flow diagrams for alginatepectin and chitosan respectively. About $0.3 \mathrm{~g}$ of acetyl salicylic acid was dissolved in $100 \mathrm{~mL}$ double distilled water. After the complete dissolution, $2 \mathrm{~g}$ of sodium alginate and $3 \mathrm{~g}$ of pectin were mixed and homogenized thoroughly to get alginate-pectin composition of 40:60 on dry basis using rotary type laboratory mixer (Ultra Turrax, T25 basis; IKA Labor technic.). To get chitosan drug loaded microcapsules, about $0.3 \mathrm{~g}$ of acetyl salicylic acid (aspirin) was dissolved in $100 \mathrm{~mL} 2 \%$ glacial acetic acid solution. After the complete dissolution, $2 \mathrm{~g}$ of chitosan was mixed thoroughly using ultrasonic wave sonicator to get encapsulated drug emulsion with chitosan. After mixing the polymer-drug mixture was kept under vacuum to remove all the entrapped air bubbles. Then alginate- pectin-drug mix was atomized through nozzle using nitrogen gas at a pressure of $300 \mathrm{kPa}$ into gently agitated $1.0 \mathrm{M}$ calcium chloride solution to ensure covalent cross link among calcium chloride ion, alginate and pectin. It forms discrete aspirin encapsulated microcapsules upon contact with calcium chloride solution. After completing the atomization process, encapsulated particles were allowed to stay inside the calcium chloride solution for 3-4 hours to harden the encapsulated and gelled microcapsules. Into the chitosandrug emulsion mix $150 \mathrm{~mL}$ of $5 \%$ glutaraldehyde solution was poured slowly. Glutaraldehyde was acted as a cross linker for chitosan. While pouring, the emulsion mix was stirred using magnetic stirrer at its maximum speed. After pouring all the glutaraldehyde solution the whole mix was continuously stirred for 24 hours to harden the encapsulated and gelled microcapsules. It forms discrete aspirin encapsulated microcapsules upon contact with glutaraldehyde solution. Then the microcapsules were harvested by centrifuging the solution at $5000 \mathrm{rpm}$ for 10 minutes and washed thoroughly using distilled water. Finally the microcapsules were dried using microwave vacuum drying method.

\section{Microwave Vacuum Drying}

Drying of microcapsules was conducted at 300 watts microwave power in a vacuum microwave dehydrator (Model 1.8, EnWave Corporation, Vancouver, Canada). About $30 \mathrm{~g}$ of drug encapsulated microcapsules were spread evenly in a glass Petri dish of diameter $14 \mathrm{~cm}$. This was placed inside the drying chamber. The absolute pressure maintained during the process was $3.3 \mathrm{kPa}$. After creating this vacuum level, microwave energy was supplied to the sample to assist the drying process. Drying was continued until the sample reached less than 1-2 \% (w.b) moisture content. In between, the drying process was stopped and the microcapsules were mixed gently to get even drying. The temperature was maintained below $40^{\circ} \mathrm{C}$ throughout the drying process.

\section{Morphology Analysis of Dry Microcapsule}

Scanning electron microscopic (SEM) graphs of dried microcapsules were obtained using Hitachi S4700 Field emission SEM (Japan) for morphology analysis. The dried sample was placed in an air tight desiccator, which had silica gel to remove moisture. The sample was kept in this condition until they attained a constant weight. Small amount of dried microcapsules were dispersed into alcohol to separate individual particle on previously fixed glass plates on iron stub. The alcohol was allowed to evaporate and then the microcapsules were made electrically conductive by coating, in a vacuum, with a thin layer of gold for $40 \mathrm{~s}$. Images were obtained at an excitation voltage of 20 $\mathrm{kV}$ at different magnifications varying from 350 to 6000 . 


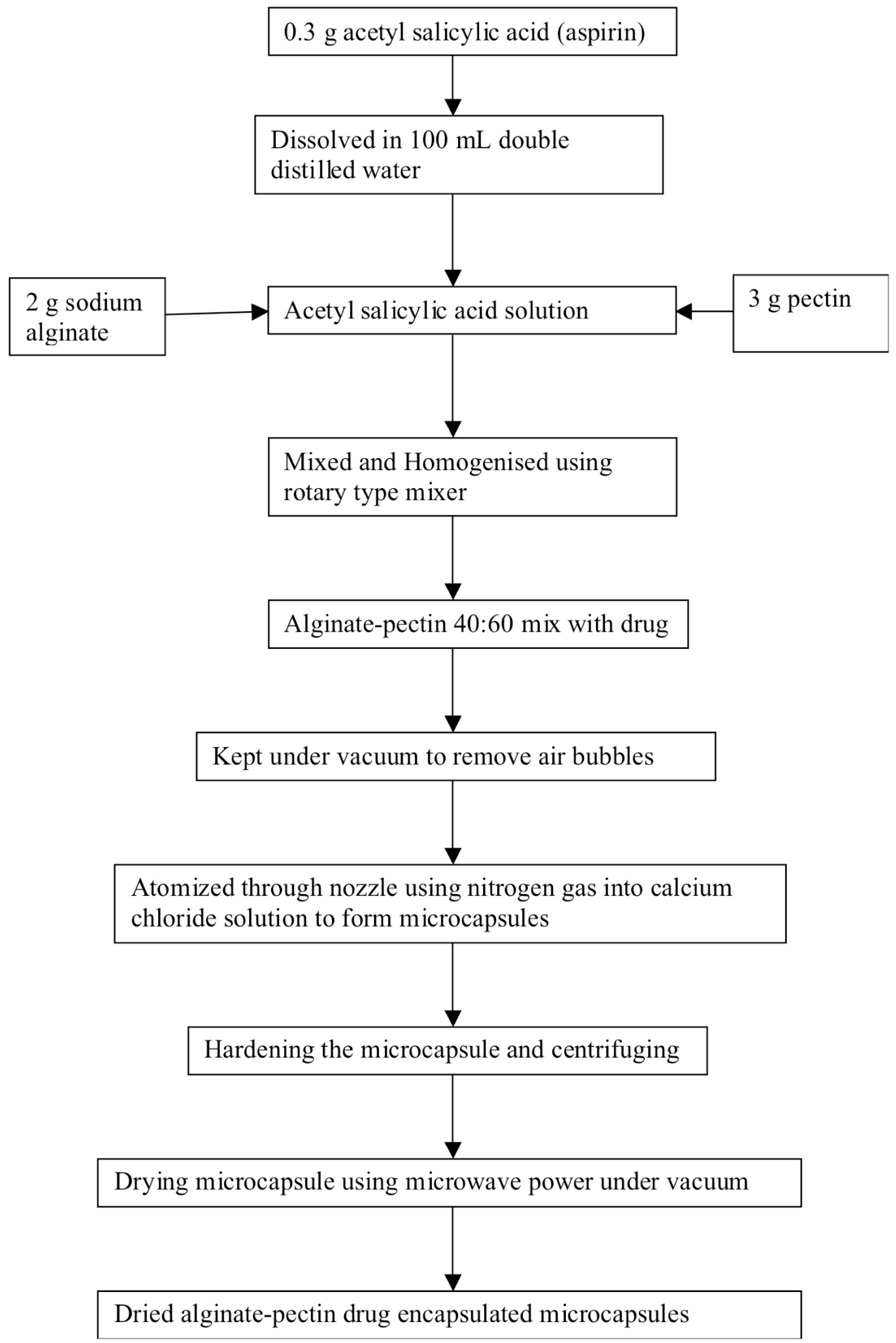

Fig. (1a). Process flow diagram of alginate-pectin microcapsule preparation.

\section{X-Ray Diffraction Analysis}

X-ray diffraction patterns of dried alginate-pectin and chitosan microcapsules were obtained at room temperature using a Rigaku Multiflex powder diffractometer $(\mathrm{CuK} \alpha$ radiation generator) operated at a voltage of $40 \mathrm{kV}$. Finely ground microcapsules were analyzed in two theta angle range of 6-60 and the process parameters were set as: scan step size of $0.02(2 \theta)$ and scan step time of $0.05 \mathrm{~s}$. It was found that there were no peaks below and above the angles 6 and 60 respectively. So this range was selected for scanning. Same way pure alginate, pectin, chitosan and aspirin samples were also analyzed. 


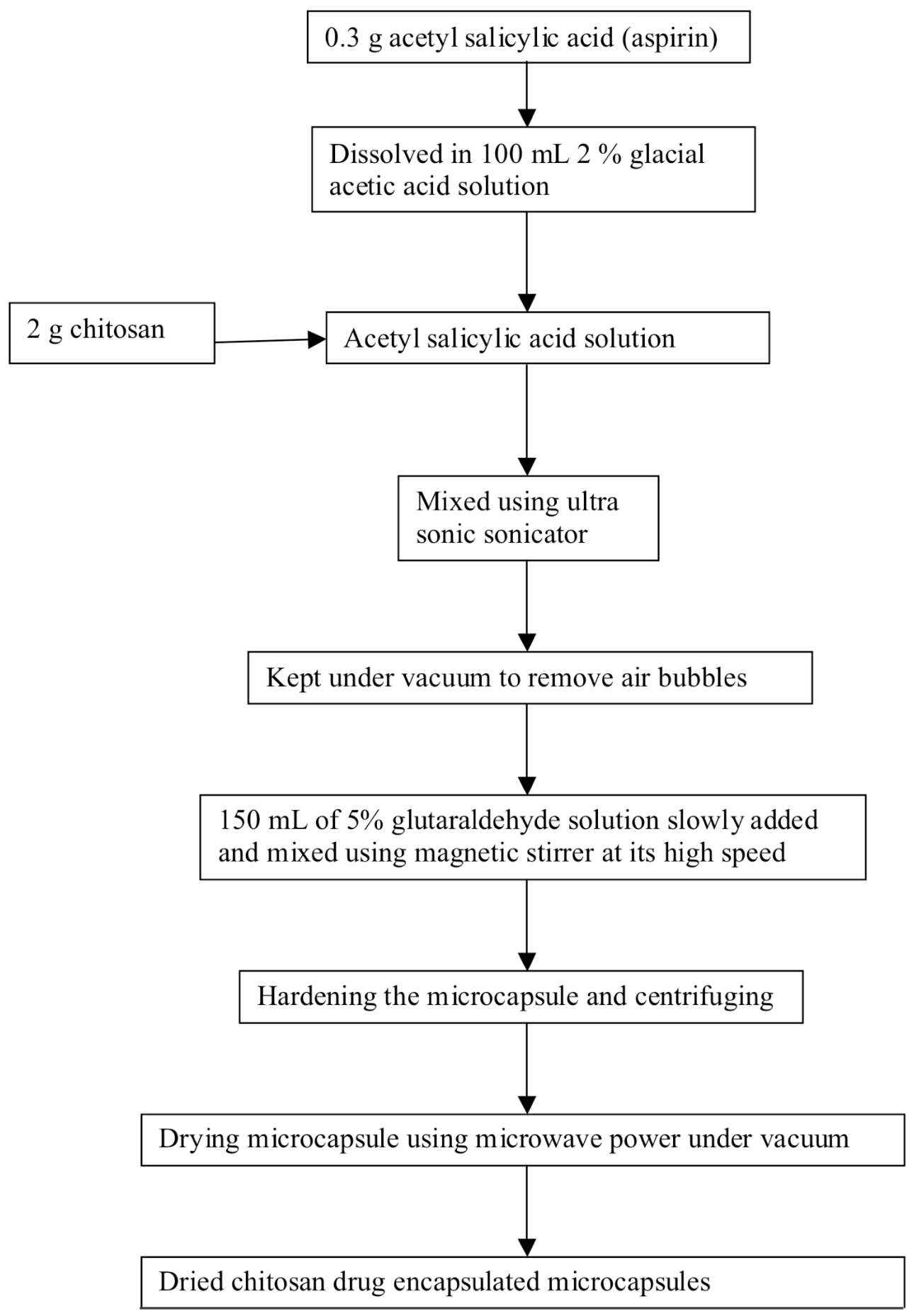

Fig. (1b). Process flow diagram of chitosan microcapsule preparation.

\section{FTIR Spectroscopy Analysis}

FTIR spectra of dried alginate-pectin and chitosan microcapsules were obtained using a FTIR spectrometer (Perkin Elmer 2000 Infrared Spectrophotometer). Dried microcapsules and pure raw materials were previously ground and mixed thoroughly with potassium bromide at 1:5 (sample: $\mathrm{KBr}$ ) ratio, respectively. The transparent $\mathrm{KBr}$ discs were prepared by compressing the powders, under the force of 2.8-3 MPa for 3-5 min in a hydraulic press. Fifty scans were obtained at a resolution of $2 \mathrm{~cm}^{-1}$ from $4000-400 \mathrm{~cm}^{-1}$ wave number.

\section{Drug Release Study}

Drug release pattern of each alginate-pectin and chitosan microcapsules were studied at three different $\mathrm{pH}$ levels to identify where it could release maximum amount of drug. The aim of this work at this point was focused on to get maximum release. Therefore the buffers with 1.2 (stimulating the gastric $\mathrm{pH}$ ), 8.2 (stimulating the intestinal $\mathrm{pH}$ ) and $7.4 \mathrm{pH}$ (neutral $\mathrm{pH}$ ) levels were prepared to create different release conditions. For $\mathrm{pH}$ 1.2: $0.1 \mathrm{M} \mathrm{HCl}$ buffer, $\mathrm{pH}$ 7.4: PBS (phosphate buffer saline) and $\mathrm{pH}$ 8.2: phosphate buffer were used. $0.5 \mathrm{~g}$ of dried microcapsules of each 
composition was taken in $100 \mathrm{~mL}$ beaker. About $50 \mathrm{~mL}$ of respective buffer solution was added to each of the capsules. The drug release was carried at $37^{\circ} \mathrm{C}$ for all the buffers. After soaking the microcapsules in respective buffer solutions, at every 30 minutes, $1 \mathrm{~mL}$ of sample was withdrawn from each and it was replaced with $1 \mathrm{~mL}$ of respective buffer solutions. The samples were taken for up to 6 hours. To each $1 \mathrm{~mL}$ of the samples, $10 \mathrm{~mL}$ of $1 \mathrm{~N}$ sodium hydroxide was added. This mixture was heated just to boil and then cooled before reading for the aspirin amount that released from each microcapsules composition. The concentration of aspirin in the sample was read using UV spectrophotometer at $293 \mathrm{~nm}$. Each drug release study was repeated for 5 times and the average was presented in the result.

\section{RESULTS AND DISCUSSION}

\section{Morphology Analysis of Dried Microcapsule}

Fig. (2) shows the morphology of acetyl salicylic acid encapsulated dried alginate - pectin microcapsule. This figure shows both the surface (upper figure) and inner view (bottom figure) of the microcapsule at $\mathrm{x} 3.0 \mathrm{k}$ and $\mathrm{x} 450$ magnification respectively. It can be observed that inner view shows the encapsulated drug crystals present inside the microcapsule and one such crystal has been shown by arrow mark in the figure. Also it shows that the internal structure of the microcapsule is porous and the pores are interconnected. This kind of structure is helpful for the drug delivery. The surfaces of the microcapsules (upper figure) are appeared to be rough and the particles are not in perfect spherical shape. Pectin contains other neutral sugars of xylose, galactose and arbinose in the structural side chains. These structures lead the pectin molecules with smooth hairy regions. This nature of the pectin molecular structure might be the reason for getting elongated shape microcapsules instead of spherical shape.

Fig. (3) shows a sample of SEM micrographs of acetyl salicylic acid encapsulated dried chitosan microcapsules. These micrographs were obtained to investigate the surface morphology of the microcapsules. Chitosan microcapsules were prepared in the size ranges $40-100$ micrometers. Both upper and bottom figure show the surface features of the chitosan microcapsules at $1.5 \mathrm{k}$ and 600 magnifications. The surfaces of the microcapsules are appeared to be rough. Also they are not in perfect spherical shape like alginate-pectin microcapsules. Sphericity and surface smoothness of chitosan capsules might be affected by stirring rate of the dispersion medium during cross linking and mixing during the drying process to obtain uniform drying. In general covalently cross-linked chitosan gives porous structure [30]. Due to this porous nature they are considered for drug delivery by means of drug diffusion. When aqueous solution diffuses into interior of the microcapsules by capillary, the drug might be dissolved and released though the same path. Presence of drug crystals inside the chitosan microcapsules could not be confirmed from this surface morphology. However, cross section of the alginate-pectin microcapsule shows the presence of drug crystals of 1- 3 micron in Fig. (1, bottom) with arrow mark. All the microcapsules both chitosan and alginate-pectin exhibit a folded structure, wrinkle type of crevices and crack like porous structure on

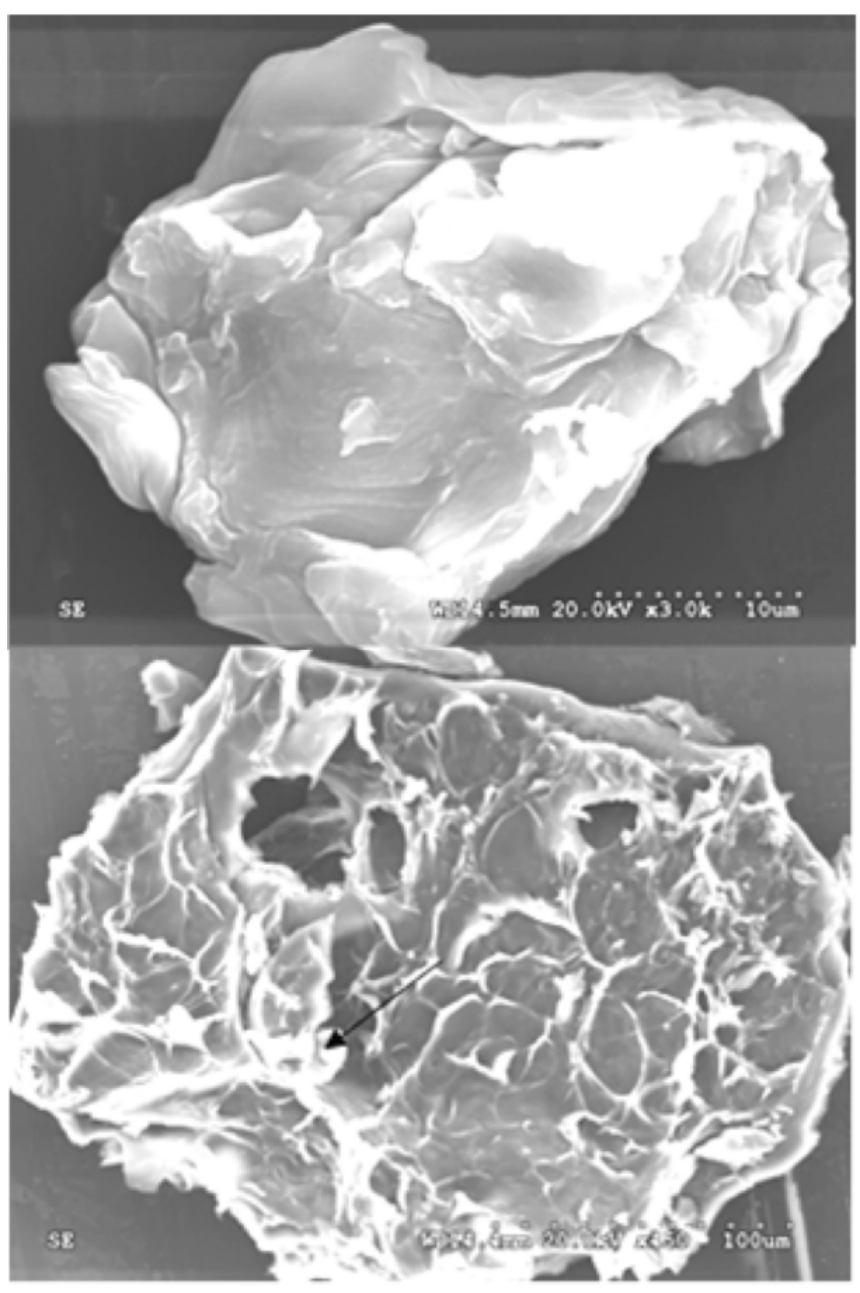

Fig. (2). Scanning electron microscopic view of drug loaded Alginate-pectin (40:60) microcapsule.

its surface. Since the sphericity of microcapsules was lost during gelation and drying, microcapsules with holes could be formed; it could not seen by SEM. This may allows the encapsulated drug to leak.

\section{X-Ray Diffraction Analysis}

Fig. (4) shows the X- ray diffraction pattern of drug encapsulated microcapsules with alginate - pectin and chitosan also pure pectin, alginate, chitosan and acetyl salicylic acid. Drug loaded microcapsules show the mix of crystalline and amorphous pattern. Pure sodium alginate has crystalline peaks at 13 and $21^{\circ}$ two theta angle. Pure chitosan has characteristic peaks at $20^{\circ}$ two theta angle. Pure aspirin has strong peaks at $8^{\circ}$ and $16^{\circ}$ two theta angles. However, the microcapsules with both chitosan and alginate-pectin show more like amorphous pattern than like crystalline. Alginatepectin patterns show the crystallinity of pectin but there is a marked reduction compared to the parent pectin peaks. Similarly salicylic acid also shows reduction in crystallinity. Characteristic peak of chitosan became wider. Since the percentage of chitosan was very high compared to the drug percentage encapsulated, the crystalline nature of the drug was diminished in the X-ray diffraction pattern. However the presence of drug was proved by conducting FT-IR analysis. Overall the microcapsules showed the amorphous nature 


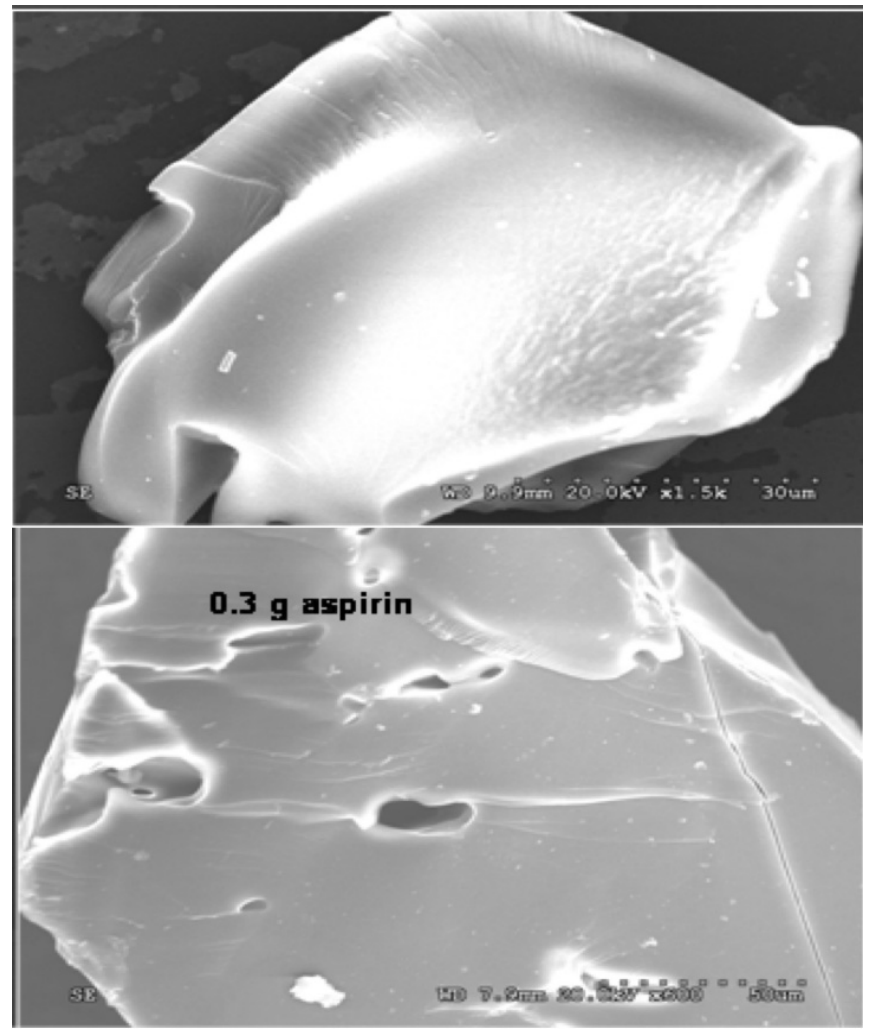

Fig. (3). Scanning electron microscopic view of drug loaded chitosan microcapsule.

after processing. This might reduce the stability of the drug. Further in depth study on this regard is necessary.

\section{FTIR Spectroscopy Analysis}

Fig. (5) shows the FTIR spectroscopy spectrum of drug loaded alginate-pectin and chitosan microcapsules. The bands at 1620 and $1420 \mathrm{~cm}^{-1}$ present in the IR spectrum of sodium alginate are assigned to symmetric and symmetric stretching peaks of carboxylate salt groups. In addition, the bands around $1320 \mathrm{~cm}^{-1}$ (C-O stretching), $1120 \mathrm{~cm}^{-1}$ (C-C stretching), $1090 \mathrm{~cm}^{-1}$ (C-O stretching), $1020 \mathrm{~cm}^{-1}$ (C-O-C stretching), and $950 \mathrm{~cm}^{-1}$ (C-O stretching) are attributed to its saccharide structure [31]. In the FTIR spectrum of pectin, bands related to $\mathrm{C}-\mathrm{O}$ stretching of carboxyl group could be observed at $1619 \mathrm{~cm}^{-1}$ [32]. FTIR spectrum of drug loaded microsphere confirms the presence of acetyl salicylic acid. Several strong vibrations are presented at $1770(\mathrm{C}=\mathrm{O}$ stretch), 1600 ( $\mathrm{C}=\mathrm{C}$ stretch), 1580 (OCO anti symmetric stretch), 1400 (OCO symmetric stretch) and 1238, 1212, and $1184 \mathrm{~cm}^{-1}$ (C-O and C-C stretching modes) in the spectrum of the pure aspirin. Similar peaks are appeared in the spectrum of drug loaded-microcapsules.

The main characteristic bands of chitosan amine groups are at $1540 \mathrm{~cm}^{-1}$ and the carbonyl groups are at $1650 \mathrm{~cm}^{-1}$. Amines are bases, and their corresponding conjugate acid "onium" salts are often formed. These derivatives show strong, broad N-H stretching absorptions in the 2250 to 3000 $\mathrm{cm}^{-1}$ region. The aldehyde groups form covalent imine bonds with the amino groups of chitosan via a Schiff reaction. The broad band at $3500-3400 \mathrm{~cm}^{-1}$ was due to the stretching vibration of $-\mathrm{NH}_{2}$ and $-\mathrm{OH}$ groups. Also $-\mathrm{NH}_{2}$ (scissoring)

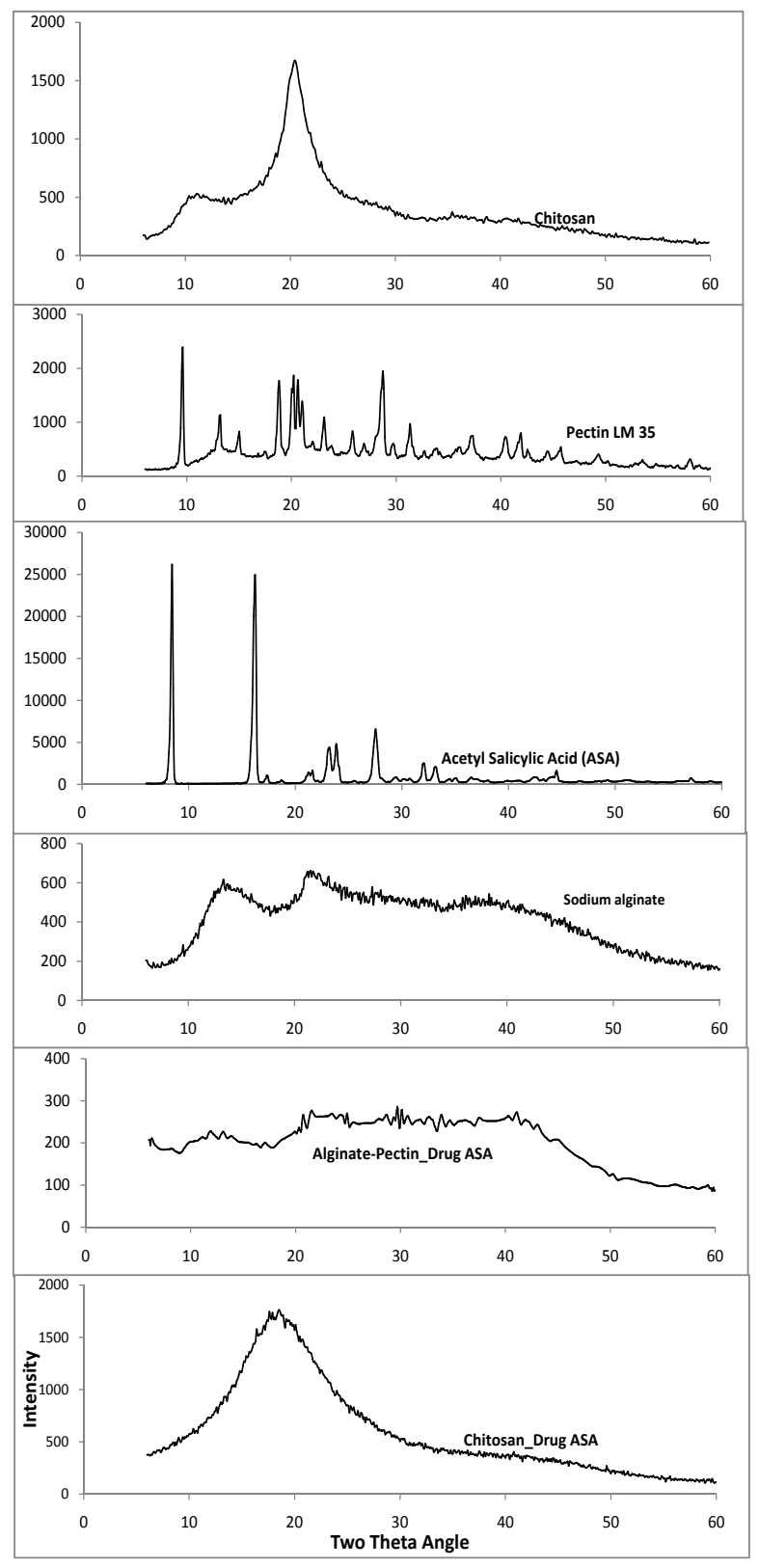

Fig. (4). X-ray diffraction analysis of drug loaded chitosan and alginate-pectin microcapsules.

$\mathrm{N}-\mathrm{H}$ (wagging) of amine groups present in the chitosan are occurred at $1550-1650 \mathrm{~cm}^{-1}$ and $900-660 \mathrm{~cm}^{-1}$. The bands at $1100-1000 \mathrm{~cm}^{-1}$ are due to the saccharide structure of the chitosan. The aldehyde bond of $\mathrm{C}=\mathrm{O}$ is appeared at $1700 \mathrm{~cm}^{-1}$. Also the broad absorption band between $4000-3000 \mathrm{~cm}^{-1}$ is obtained due to the glutaraldehyde cross linking solution. Several strong vibrations at $1600(\mathrm{C}=\mathrm{C}$ stretch $), 1580$ (OCO anti symmetric stretch), $1210-1320 \mathrm{~cm}^{-1}(\mathrm{O}-\mathrm{C})$ and $1184 \mathrm{~cm}^{-1}$ (C-C stretching modes) are the characteristics spectrum of the pure aspirin.

\section{Drug Release Study}

Fig. (6) shows the percentage of drug released from the chitosan and alginate pectin microcapsules at $\mathrm{pH} 7.4$ in PBS buffer. The data in this figure representing the average of the release performed for 5 times. The standard deviations 
obtained for the alginate-pectin and chitosan release study were 0.42 and 0.26 respectively. It shows that maximum release of $40 \%$ was obtained from the alginate pectin and 38 $\%$ from chitosan microcapsules. In general both the microcapsules showed controlled release of drug and it increased gradually with the time.

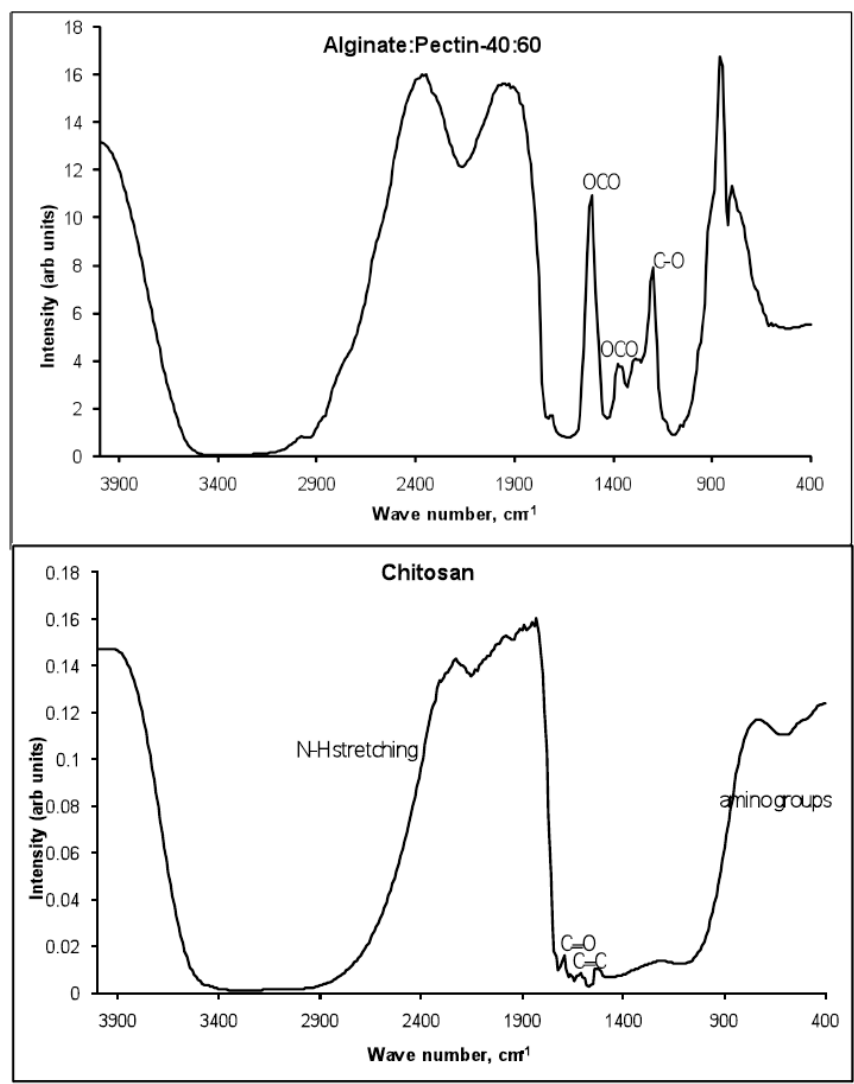

Fig. (5). FTIR spectra of drug leaded chitosan and alginate-pectin microcapsules.

Fig. (7) shows the percentage of drug released from the microcapsules at $\mathrm{pH} 8.2$ (intestinal $\mathrm{pH}$ ) in phosphate buffer. The standard deviations of five times repeated release study were 0.51 and 0.36 for the alginate-pectin and chitosan microcapsules respectively. Alginate pectin combination shows $44 \%$ of drug released in 360 minutes, where as chitosan shows only $20 \%$. The overall drug release process was influenced by the physical and mechanical properties of the gel barrier that formed around the capsules. Increased in amount of pectin caused the gel barrier poor and increased the drug release percentage. To get more control over the drug delivery the current polymer matrix could be improved in such way by increasing its gelation time and then the gel strength. Overall, compared to $\mathrm{pH} 7.4$ the percentage of drug released in alkaline $\mathrm{pH}$ is less for chitosan and more for alginate-pectin microcapsules. It showed that the chitosan has strong gel barrier against alkaline pH. Fig. (7) also shows that the release profile of chitosan microcapsule in alkaline $\mathrm{pH}$ was very irregular. In practical the drug release from covalently cross linked chitosan is controlled by crosslinking density. Higher the density, lower the release rate and vice versa. Inter chains formed during cross-linking and gave more interactions and inhibited swelling. Thus, crosslinked chitosan exhibits $\mathrm{pH}$ sensitive nature for its swelling and drug release. Poor drug release profile could also be obtained if most of the amino groups involved in the crosslinking. When the chitosan microcapsules were soaked in the alkali $\mathrm{pH}$ there might be a chance of further cross-linking of amino groups present in the chitosan. This might be the reason for lower drug release rate at alkaline $\mathrm{pH}$.

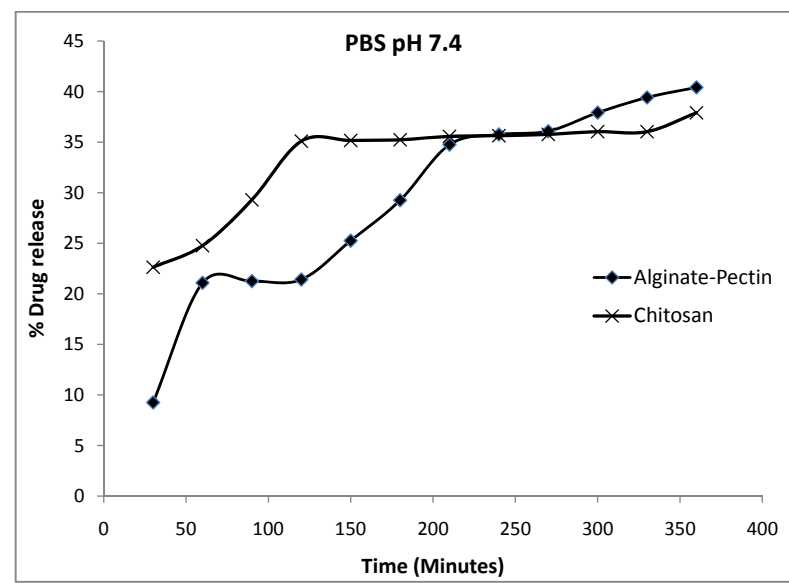

Fig. (6). Drug release profile of alginate-pectin and chitosan microcapsules in PBS solution at $\mathrm{pH}$ 7.4.

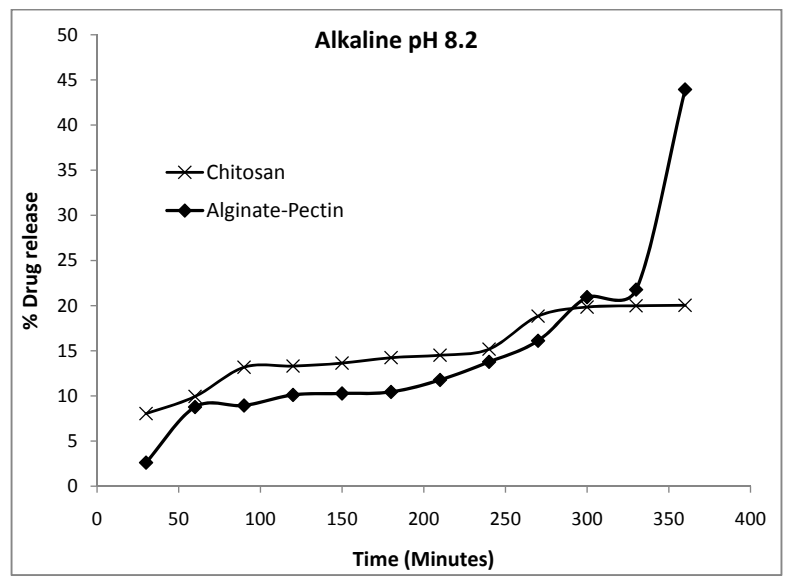

Fig. (7). Drug release profile of alginate-pectin and chitosan microcapsules in alkaline solution at $\mathrm{pH} 8.2$.

Fig. (8) shows the percentage of drug released from microcapsules at $\mathrm{pH} 1.2$ (gastric $\mathrm{pH}$ ) in $0.1 \mathrm{M} \mathrm{HCl}$ buffer. The data plotted were an average of 5 sets of release obtained with standard deviation of 0.23 and 0.57 for the alginate-pectin and chitosan microcapsules respectively. Here the maximum $60 \%$ of drug release was obtained for alginate: pectin and $56 \%$ for chitosan microcapsule. Both the microcapsules showed more release percentage in acidic $\mathrm{pH}$ than in alkaline and neutral $\mathrm{pH}$. This result is inconsistent with the results of slower release from alginate-pectin capsules in acidic solution than in alkaline reported by Liu and Krishnan [33] and Bodmeier and Paeratakul [34]. However Østberg and others [35] reported that faster release in acidic solution, which is similar to this report. This kind of variation could be possible due to the difference in chemical composition of commercially available alginate and pectin in terms of guluronic/mannuronic acid ratios and the level of free acid groups. In general the drug release process was influenced by the physical and mechanical properties of the gel barrier that formed around the capsules and its interaction 
with the drug. Stronger the interaction slower the drug release. At neutral and alkaline $\mathrm{pH}$, drug release from hard capsules containing alginate-pectin was controlled by the formation of a hydrated viscous layer around the capsules, which acted as a barrier to drug release by opposing the penetration of water into the matrices and the movement of dissolved solutes out of the matrices. Chitosan and its formulations have the property to float and swell gradually in acid medium [36]. Therefore, at acidic $\mathrm{pH}$ the chitosan microcapsules had more swelling than in alkali $\mathrm{pH}$, and released more drugs. If the drug delivery system has sensitive swelling in an acidic environment it controls the delivery and can able to make the system more useful to deliver in the gastrointestinal track. It could be possible by changing the cross linking density by introducing additional polymer in the inter chain between the chitosan and crosslinker. The results suggested that the structure of the capsules in different $\mathrm{pH}$ levels was varying each other to give different release percentage. The percentage of drug released from the microcapsules was dependent on the summative effect of the physicochemical properties of the drug and the composition of microcapsule matrix.

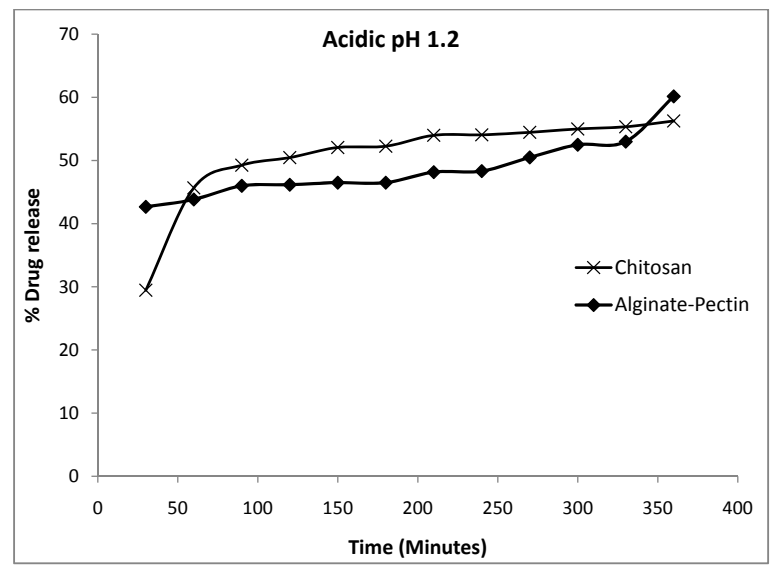

Fig. (8). Drug release profile of alginate-pectin and chitosan microcapsules in acidic solution at $\mathrm{pH} 1.2$.

\section{CONCLUSIONS}

Alginate-pectin and chitosan microcapsules were successfully prepared using internal gelation method. The drug release was affected by release medium condition as well as the properties of the polymer, polymer cross-linking density and drug. This work showed that more drug release was obtained for acidic $\mathrm{pH}$ environment. The contribution of each release mechanism to the overall drug release process was influenced by the physical and mechanical properties of the gel barrier that formed around the capsules. Morphology of alginate-pectin and chitosan microcapsules showed folded structure, wrinkle type of crevices and crack like porous structure on its surface. Micrographs confirmed the presence of drug crystals. FTIR spectrum result also confirmed the same. Overall, the molecular structures of the microcapsules were amorphous. In this study, controlled release of drug was achieved up to 360 minutes by the gradual increase from time to time for three $\mathrm{pH}$ levels. The structure of the microcapsules in different $\mathrm{pH}$ levels was varying each other to give different drug release percentage. Based on the above results, it may be concluded that alginate-pectin is more suitable for targeted drug release at intestine than chitosan. Over all alginate-pectin gave more release percentage in all tested release medium compared to chitosan.

\section{ACKNOWLEDGEMENT}

The financial support provided by Natural Science and Engineering Research Council of Canada (NSERC) for conducting this research is gratefully acknowledged.

\section{REFERENCES}

[1] Polk A, Amsden B, Deyao K, Peng T, Goosen MFA. Controlledrelease of albumin from chitosan alginate microcapsules. J Pharm Sci 1994; 83: 178-85.

[2] Iannuccelli V, Coppi Vandelli MA, Leo E, Bernabei MT. Bead coating process via an excess of cross-linking agent. Drug Dev Ind Pharm 1995; 21: 307-2322.

[3] Hodsdon AC, Mitchell JR, Davies MC, Melia CD. Structure and behavior in hydrophilic matrix sustained release dosage forms. 3 . The influence of $\mathrm{pH}$ on the sustained release performance and internal gel structure of sodium alginate matrix. J Control Release 1995; 33: 143-52.

[4] Simon LD, Ruizcardona L, Topp EM, Stella VJ. Effect on pH on theophylline release from partially esterified alginic acid matrices. Drug Dev Ind Pharm 1995; 20: 2341-51.

[5] Park HY, Choi CR, Kim JH, Kim WS. Effect of pH on drug delivery from polysaccharide tablets. Drug Deliv 1998; 5: 13-18.

[6] Coppi G, Iannuccelli V, Leo E, Bernabei MT, Cameroni R. Protein immobilization in crosslinked alginate microparticles. J Microencapsul 2002; 19: 37-44.

[7] Boadi DK, Neufeld RJ. Encapsulation of tannase for the hydrolysis of tea tannins. Enzyme Microb Technol 2001; 28: 590-95.

[8] Albarghouthi M, Fara DA, Saleem M, El-Thaher T, Matalka K, Badwan A. Immobilization of antibodies on alginate-chitosan beads. Int J Pharm 2000; 206: 23-34.

[9] Gray CJ, Dowsett J. Retention of insulin in alginate gel beads. Biotechnol Bioeng 1988; 31: 607-12.

[10] Miyazaki S, Nakayama A, Oda M, Takada M, Attwood D. Drug release from mucosal adhesive tablets of chitosan and sodium alginate. Int J Pharm 1995; 118: 257-64.

[11] Chickering DE, Jacob JS, Desai TA, et al. Bioadhesive microspheres: III. "In vivo" transit and bioavailability study of drug-loaded alginate and poly(fumaric-co-sebacic anhydride) microspheres. J Control Release 1997; 48: 35-46.

[12] Wong TW, Chan LW, Lee HY, Heng PWS. Release characteristics of pectin microspheres prepared by an emulsification technique. J Microencapsul 2002; 19(4): 511-22

[13] Wan LSC, Heng PWS, Chan LW. Influence of hydrophilelipophile balance on alginate microspheres. Int J Pharm 1993; 95 77-83.

[14] Wan LSC, Heng PWS, Chan LW. Surfactant effects on alginate microspheres. Int J Pharm 1994; 103: 267-75.

[15] Chan LW, Heng PWS, Wan LSC. Effect of cellulose derivatives on alginate microspheres prepared by emulsification. J Microencapsul 1997; 14: 545-55.

[16] Madziva H, Kailasapathy K, Phillips M. Alginate-pectin microcapsules as a potential for folic acid delivery in foods. $\mathrm{J}$ Microencapsul 2005; 22(4): 343-51

[17] Kas HS. Chitosan: properties, preparation and application to microparticulate systems. J Microencapsul 1997; 14: 689-711.

[18] Singla AK, Chawla M. Chitosan: some pharmaceutical and biological aspects_-an update. J Pharm Pharmacol 2001; 53: 104767.

[19] Kato Y, Onishi H, Machida Y. Application of chitin and chitosan derivatives in the pharmaceutical field. Curr Pharm Biotechnol 2003; 4: 303-9.

[20] Chandy T, Wilson RF, Rao GH, Das GS. Changes in cisplatin delivery due to surface-coated poly(lactic acid)- poly(epsiloncaprolactone) microspheres. J Biomater Appl 2002; 16: 275-91.

[21] Illum L, Jabbal-Gill I, Hinchcliffe M, Fisher AN, Davis SS. Chitosan as a novel nasal delivery system for vaccines. Adv Drug Deliv Rev 2001; 51: 81-96.

[22] Sinha VR, Singla AK, Wadhawan S, Kaushik R, Kumria R, Bansal $\mathrm{K}$, Dhawan S. Review: Chitosan microspheres as a potential carrier for drugs. Int J Pharm 2004; 274: 1-33. 
[23] Yan-Fei L, Ke-Long H, Dong-Ming P, Ding P, Gui-Yin L. Preparation and characterization of glutaraldehyde cross-linked Ocarboxymethylchitosan microspheres for controlled delivery of pazufloxacin mesilate. Int J Biol Macromol 2007; 41: 87-93.

[24] Janne PA, Mayer RJ. Chemoprevention of colorectal cancer. N Engl J Med 2000; 342: 1960-8.

[25] Charles HH, Mark LD. Fuster V. Aspirin as a Therapeutic Agent in Cardiovascular Disease: A Statement for Healthcare Professionals from the American Heart Association. Circulation 1997; 96: 2751-

[26] Bair WB, Hart N, Einspahr J, Liu G, Dong Z, Alberts D. Inhibitory effects of sodium salicylate and acetylsalicylic acid on UVBinduced mouse skin carcinogenesis. Cancer Epidemiol Biomarkers Prev 2002; 11(12); 1645-52.

[27] Morgan G. An aspirin a day. New Sci 2004; 36-9.

[28] Murono S, Yoshizaki T, Sato H, Takeshita H, Furukawa M, Pagano JS. Aspirin inhibits tumor cell invasiveness by epstein- barr virus latent membrane protein through suppression of matrix metalloproteinase-9 expression. Cancer Res 2000; 60(9): 2555-61.

[29] Tsai J, Chuang S, Hsu M, Sheu H. Distribution of salicylic acid in human stratum corneum following topical application in vivo: a comparison of six different formulations. Int J Pharm 1999; 188(3): 145-53.

[30] Thacharodi D, Rao KP. Propanolol hydrochloride release behaviour of crosslinked chitosan membranes. J Chem Technol Biotechnol 1993; 58: 177-81.

[31] Sartori C, Finch DS, Ralph B, Gilding K. Determination of the cation content of alginate thin films by FTIR. spectroscopy. Polymer 1997; 38: 43.

[32] Takahashi T, Takayama K, Machida Y, Nagai T. Characteristics of polyion complexes of chitosan with sodium alginate and sodium polyacrylate. Int J Pharm 1990; 61: 35-41.

[33] Liu P, Krishnan TR. Alginate-pectin-poly-L-lysine particulate as a potential controlled release formulation. J Pharm Pharmacol 1990 51: 141-9.

[34] Bodmeier R, Paeratakul O. Spherical agglomerates of waterinsoluble drugs. J Pharm Sci 1989; 78: 964-7.

[35] Østberg T, Lund ME, Graffner C. Calcium alginate matrices for oral multiple unit administration: IV. Release characteristics in different media. Int J Pharm 1994; 112: 241-8.

[36] Miyazaki S, Ishii K, Nadai T. The use of chitin and chitosan as drug carriers. Chem Pharm Bull 1981; 29: 3067-9.

This is an open access article licensed under the terms of the Creative Commons Attribution Non-Commercial License (http://creativecommons.org/licenses/by$\mathrm{nc} / 3.0 /$ ) which permits unrestricted, non-commercial use, distribution and reproduction in any medium, provided the work is properly cited. 